\title{
EVALUATION OF IMMERSION PROGRAM FROM STUDENT' PERSPECTIVE IN SICHUAN UNIVERSITY, CHINA
}

\author{
Yu Man \\ School of Public Administration, Sichuan University (China)
}

\begin{abstract}
The UNIVERSITY IMMERSION PROGRAM (UIP) of Sichuan University is an international communication program. It aims to broaden the global view and cultivate global cooperation awareness of the students. UIP consists of four parts, the first is general or specialized courses provided by professors from all over the word, the second is seminars or symposiums on various topics, the third is field study and visits, and the fourth is local cultural interactions. This paper intends to evaluate UIP in students' perspective. The article evaluates four parts mentioned above by using questionnaire survey and self-report survey. This research includes three steps. Frist step is evaluating field visits and cultural interaction by using 18 self-reports. Second step is evaluating courses and seminars by collecting relevant data from results of student's evaluation related to professors teaching quality. Third step is evaluating the whole effectiveness through interview method. Findings reveal the following facts. Firstly, students are more satisfied with local cultural interactions than other three parts due to more chances will be given to communicate freely with professors and international students. Secondly, advanced technology or infrastructure will improve their satisfaction in field study and visit. Lastly, the contentment of English courses is subject to teaching style of professors or the way to organize class. In the end suggestions and strategies are put forward to improve students' satisfaction and influence of UIP.
\end{abstract}

Keywords: Student perspective, Sichuan university, evaluation, university immersion program.

\section{Introduction}

Recent years, higher education has changed a lot under the great challenge of globalization and knowledge economics. Students received higher education are going to face more difficult professional problems and compete with talents from various countries (Miranda et al 2020). It means higher educations need to cultivate both student's professional ability and inter-cultural communication ability. Based on that background, Sichuan University put forward international immersion program. This program aims to enhance communication with excellent university in other countries and cultivate cooperation, competition awareness among students. It includes four parts, one is general course taught in English; second is seminars organized by famous professors; third is field visits; fourth is local culture experience. So far, it has been held eight years successfully in summer campus. 144 top universities (such as Harvard University, Oxford University, and Cornell University) from 26 countries have involved in this program (SCU, 2019).

\section{Research question}

How students feel about this program? What they can really gain from this program after participate it? How it influence participators in the near future, whether it bring some changes to their cognition or shill. This paper will analyze these questions from the four parts described above.

\section{Culture experience evaluation}

Culture experience activities are through all the program, but it main gathered in class and in the process of Local cultural visit. Group discussion, case sharing are methods used by teachers to lead inter-culture communication in class. In the International Citizen Class, students are requested to make presentation about featured things or traditional custom in their hometown. Russian student introduced their unique ways to show welcome. Japanese student introduced their dress up convergence phenomenon in job fair, as people feel it's safe to dress same. Chinese students introduce Miao architectures which are better 
suited to living in groups and hoarding food. After classes and seminars, students visited places of interest or local special museums, for example Students visited Jinsha site as well as the giant panda breeding base, which have strong regional color and historical heritage.

Of the 18 self-reports, 12 students mentioned cultural sharing activity in class and 16 students mentioned local cultural visits. The cultural interactive activities organized by teachers purposefully are the method for students to conduct cultural communication in a concentrated and efficient way. Participants use "impress", "wonderful", and "enlighten my mind" most frequently to describe the cultural communication in the classroom. One student wrote "What impressed me most is story character analyzation in the class. Students from different countries have different opinion about the same character, even students with same cultural background have different attitudes towards the same role"; another student wrote "the cultural sharing activity in the classroom increased my ability of understanding other cultures". The local culture visit not only helps participants to understand the local culture but also to learn to get alone with people in different cultural backgrounds

Overall, cultural interactive activities were mentioned and described the most in the 18 self-reports. The activities give participants more opportunities to express themselves freely. Participants can promote their understanding of other countries and broaden their horizons through discussions, case studies, and chats. It is benefial for students to exercise their English skills, improve the ability to communicate with international students in a relaxed and pleasant atmosphere.

\section{Field visit evaluation}

Field visit refers to the object of the visit is closely related to the student's major or the courses of the UIP. For example, Huaxi School of public health discussed the similarities and differences between Chinese and foreign public health policies and practices in class. In order to learn about the development status and practice of public health in China, students visited the Yulin community health service center in Wuhou district, Chengdu city. Under the guidance of the doctors in the center, students learned about the department Settings of yulin community health service center. The foreign students showed great interest in Chinese herb and were impressed by the massage.

In 18 self-reports, 12 participants used adjectives such as "amazing"," advanced" when describing field visits. Eight participants gave detailed descriptions of some of the advanced equipment during the visit, such as registration machines and remote consultation techniques. Students from the University of Manchester also compared Chinese public health system with their own, because of the advanced Chinese medical equipment and perfect primary medical service system they saw during the visit. They believe that our country has such a perfect public medical system. It is related to a strong government in China. The British public health system runs very slow. Only private hospitals have advanced medical equipment and a fast response system, but only a few people can afford this service (Daniel, 2015). One student expressed in self-report "one day I would introduce this advanced equipment into her country and apply them to the public health system".

Through self-reports, it is easy to find that the focus of the participants is on advanced facilities and high technology in field visit. We can show the prosperity of our nation to international students through showing high-level facilities and equipment, comprehensive service system, etc. For Chinese students, the sense of ownership and national pride are enhanced.

\section{Course evaluation}

UIP courses are organized by professors from top universities or research institutes abroad. Professors must meet the following criteria to ensure the quality of teaching: With the title of doctor degree or assistant professor; working as a teacher in foreign famous universities or research institutions; Or senior scientist or principle scientist of fortune 500 enterprises. The class is made up of 50 students, and the ratio of international students to local students is 1:5. The teacher's teaching style is unique and vivid. Cases or combined with their own experience are commonly used to explain the truth. Eleven of the 18 self-reports used words like "interesting" to describe the class

A single self-report cannot quantify students' satisfaction with the course, so this paper analyzes the course from the results of students' teaching evaluation in 2016(SCU,2018).the teaching evaluation makes a comprehensive investigation on the teachers from nine aspects, such as the basic daily teaching behavior, teaching attitude, teaching method, teaching content, after-class counseling and student satisfaction. The evaluation is based on a hundred-mark system, with an interval of 90-100 being excellent and $80-90$ being good. The total average score of the 183 courses reviewed in 2016 is 81.3 . 
In 2016, national students conducted a teaching evaluation of 183 courses. From the single index score above, we can see that students scored 8.3 for" teachers' daily basic behavioral norms "and "attitudes toward teaching", which were the two highest scores among the single indexes. Students have the lowest score for the indicators of "Curriculum Understanding". "The teaching content", "course design "and "after-school tutoring "score is 8.2 between the highest and the lowest score. Through the above analysis, it concluded that the basic quality of the curriculum can be guaranteed, and teachers can organize the curriculum in a planned and purposeful manner. However, the teaching methods of teachers need to be improved. The problem that needs to be solved urgently is that students cannot fully understand the teaching content.

Some students pointed out that the foreign teachers' accent is heavy, their speech speed so faster that students can't make clear the content. Although parts of students got high score in CET-6, they still feel hard to keep up with the teacher. The interactive between students and teacher is not high. It reflects that students' ability to apply English is insufficient. Students need some time to adapt to face-to-face communication with foreign teachers and immersion teaching environment.

Table 1. 2016 UIP Teaching Evaluation Results.

\begin{tabular}{|c|c|c|c|c|c|}
\hline Single indicator & average score & $6.0 \sim 6.9$ & $7.0 \sim 7.9$ & $8.0 \sim 8.9$ & $9.0 \sim 10.0$ \\
\hline No lateness, early departure & 8.27 & 7 & 53 & 104 & 22 \\
\hline NO arbitrarily transfer courses, & 8.30 & 6 & 50 & 105 & 25 \\
\hline Strict teaching attitude & 8.30 & 6 & 52 & 104 & 24 \\
\hline Various teaching methods & 8.18 & 9 & 61 & 98 & 18 \\
\hline New teaching content, & 8.20 & 9 & 61 & 97 & 19 \\
\hline Course design & 8.20 & 8 & 63 & 95 & 20 \\
\hline After-school tutoring & 8.20 & 8 & 58 & 102 & 18 \\
\hline Curriculum Understanding" & 7.91 & 15 & 91 & 69 & 9 \\
\hline Students' overall satisfaction & 8.03 & 11 & 76 & 87 & 12 \\
\hline
\end{tabular}

\section{Seminar evaluation}

The seminar mainly focused on hot issues at home and abroad. In 2019, UIP opened a total of 76 seminars. The seminar not only struck the spark of students' wisdom, but also broadened the international horizon (Michelle, 2012). In order to gain an in-depth understanding of public diplomacy, the School of International Relations invited nine consul generals of ASEM members to conduct seminars with students on the theme of "public diplomacy".it help students to have an intuitive experience of engaging in public diplomacy, and also have a deeper understanding of bilateral relations, bilateral economic and trade, cultural, and educational cooperation.

Five of the 18 self-reports mentioned the seminar and some classmates wrote in the self-report that "this seminar has opened up students' horizons and enhanced students' understanding of the construction of the Belt and Road interconnection with Asia and Europe". While learning knowledge, students can also discover the advantages of classmates from different countries, and learning from each other. One student writes in self-report that "The students from Osaka University are rigorous in thinking and doing things seriously! The students from the University of Washington have many ideas and open thinking".

\section{Summary and suggestion}

Among the four parts of UIP, cultural experience activities are mentioned the most in student self-reports, followed by general courses, professional visits and seminars. So the most impressive thing in the whole project is the cultural experience activity. It provides students and teachers with a relaxed and pleasant atmosphere of communication and promotes students' understanding of different cultures. In trace interview, 10 participants believed that through this project, they became more confident in communicating with foreign students; two participants believed that through the sharing of cases of international students in class, they pay more attention to empathy in their daily lives and consider issues from multiple angles. 


\subsection{Promote the construction of all-English courses}

Encourage and support the transformation of bilingual courses to full English courses. The university need to strengthen students' practical English application ability, improves teachers' internationalization ability and promotes the construction of English-only courses by organizing teachers' ability improvement training and overseas study visits (Ricardo et al, 2020).

\subsection{Recruit international students from all over the world to create an international campus atmosphere}

To form an environment for students to use English outside the classroom so as to improve their English communicative ability. Some students' problems in the project are due to their lack of ability to think and solve problems. Subject committee should reform the teaching content. Professor need organize the teaching content according to the teaching syllabus, and timely incorporate the international cutting-edge academic development into the teaching content.

\subsection{Develop students' international education concept}

Pay attention to students' comprehensive application of knowledge. Adding Students' class performance, homework, mid-term and final grades, learning results after class, into evaluation system

(Wiwik,2010). It is a good way to broaden students' international horizon through participating the activities of UIP. To promote students to establish a sense of international competition and cooperation. In this way, students' participation in UIP project can be improved.

\section{References}

Daniel, S. (2015). The New Public Management Theory in the British Health Care System. Administration \& Society, 47(7), 802-826.

Michelle, B. (2012) Exploring Cross-Cultural Communication and Collaboration in an International Early Years Setting. SAGE Publications, 2(1), 76-80.

Miranda, D., Hei,C., Tabacaru,E., Sjoer, R. R., \& Jos W. (2020) .Developing Intercultural Competence Through Collaborative Learning in International Higher Education. Journal of Studies in International Education, 24(2), 190-211.

Ricardo, T., Rony, B., \& Daniel, G. (2020). Mindfulness and Compassion as Key Factors in Improving teacher's Well Being. Mindfulness, 11(7), 1049-1061.

SCU (2018). Exploration and practice of "international course week (UIP)" in Sichuan University. Retrieved April 12, 2018, from http://www.scu.edu.cn/jxcg3/sqs.htm

SCU (2019). Teachers and students of Sichuan University share knowledge and culture with 144 $\begin{array}{lllll}\text { world-class universities. } & \text { Retrieved July } 8, & \text { 2019, }\end{array}$ http://global.scu.edu.cn/?channel/63/114//2697

Wiwik, A. (2010). Reflective Evaluation of Efl Teachers Versus Their Students' Evaluation. Bina Nusantara University, 4(1), 12-24. 